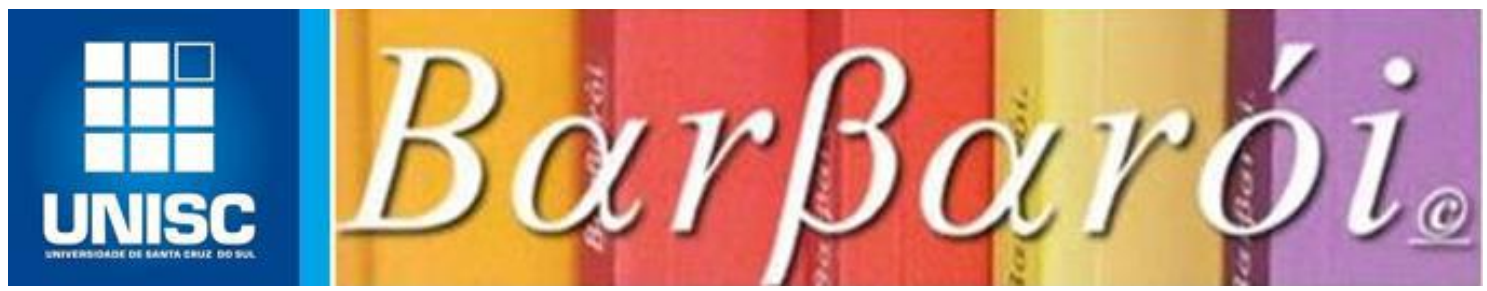

\title{
COMISSÃO SETORIAL DE AVALIAÇÃO DO COLÉGIO POLITÉCNICO (UFSM): DIAGNÓSTICO ORÇAMENTÁRIO-FINANCEIRO
}

DOI: http://dx.doi.org/10.17058/barbaroi.v1i53.12404

\author{
Juliano Molinos de Andrade \\ Universidade Federal de Santa Maria - UFSM - Brasil \\ Adriane Terezinha Filipetto \\ Universidade Federal de Santa Maria - UFSM - Brasil \\ Olga Etelvina da Costa Rohde \\ Universidade Federal de Santa Maria - UFSM - Brasil \\ Francisco Nilton Gomes de Oliveira \\ Universidade Federal de Santa Maria - UFSM - Brasil
}

$*$

\section{Resumo}

Este estudo tem como objetivo analisar o diagnóstico orçamentário-financeiro da Comissão Setorial de Avaliação do Colégio Politécnico, vinculado à Universidade Federal de Santa Maria, a fim de identificar as ações da referida Comissão no direcionamento dos recursos financeiros, oriundos da Comissão Própria de Avaliação da instituição. Do ponto de vista metodológico, esta é uma pesquisa do tipo investigativo-documental com abordagem descritivo-quantitativa, valendo do método descrito e pela ótica de um estudo de caso no Colégio Politécnico/UFSM. Para coleta dos dados foram utilizados indicadores do Sistema de Informações Educacionais ${ }^{1}$, obtidos junto à Direção Administrativa do Órgão. Esta análise permitiu a divulgação do orçamento financeiro da CSA/Politécnico, bem como a demonstração do uso do recurso financeiro direcionado às ações e propósitos estabelecidos no planejamento estratégico da UFSM.

Palavras-chave: Colégio Politécnico da UFSM. Comissão Própria de Avaliação (CPA). Comissão Setorial de Avaliação (CSA). Diagnóstico Orçamentário-Financeiro.

\footnotetext{
${ }^{1}$ O SIE é um sistema interno e integrado que abrange várias áreas que contemplam diversos módulos. Possui um sistema workflow associado à Gestão de Documentos, o que possibilita a automação dos processos de trabalho na UFSM.
} 


\section{Introdução}

O processo de avaliação pode ser entendido como uma forma constante de se verificar o andamento de uma determinada ação. Entende-se que um processo como este se faz necessário na medida em que permite uma verificação permanente de tudo aquilo que é resultante de uma atividade. O processo de avaliação está relacionado à produção de informações sobre determinada realidade e é algo que está bastante presente no cotidiano das diversas organizações, bem como das instituições de ensino. Segundo Davis e Grosbaum (2002) é o processo de avaliação que revela se a instituição de ensino está cumprindo o seu papel e oferecendo educação de qualidade. Tal assertiva se afirma com mais intensidade ao se tomar como referência a avaliação do ensino, levando-se em consideração suas especificidades e o atual momento de atribuição de novas diretrizes para essa finalidade.

Diante disso, para apuração do alcance dos objetivos e metas estabelecidos nas políticas públicas, mecanismos de avaliação de programas são empregados como subsídios à decisão de continuidade ou mudança de rumos, tendo em vista a necessidade de prestação de um serviço público de qualidade e excelência na aplicação de recursos. Com vistas a implementar a sistemática de avaliação da educação superior, em 2004, a Lei $\mathrm{n}^{\circ} 10.861$ institui o Sistema Nacional de Avaliação da Educação Superior (SINAES), com o objetivo de melhorar a qualidade da educação superior no Brasil.

Neste contexto, tem-se o caso da CSA/Politécnico. A Universidade Federal de Santa Maria (UFSM), comprometida com a Avaliação Institucional, apresenta a cada ano o relatório de avaliação, dando destaque às ações desenvolvidas pela Comissão Própria de Avaliação (CPA) e Comissões Setoriais de Avaliação (CSAs), atitude imprescindível para que o processo de Avaliação Institucional ocorra de forma dinâmica e contínua. A UFSM tem hoje quinze Unidades Universitárias, bem como possui duas unidades de educação básica, técnica e tecnológica, sendo uma delas o Colégio Politécnico, onde se optou por realizar este trabalho.

O objetivo geral deste estudo é analisar o diagnóstico orçamentário-financeiro da CSA/Politécnico, vinculado à UFSM, no período de 2015 a 2017. Esta investigação visa esclarecer e publicizar os dados orçamentário-financeiros da referida Comissão, com indicadores da aplicação dos recursos no auxílio do desenvolvimento de estudos, contribuindo para as ações de ensino, pesquisa e extensão.

A principal contribuição deste trabalho visa fornecer informações complementares que possibilitem à CSA/Politécnico identificar ações a serem mantidas, revistas ou intensificadas com vistas ao alcance dos propósitos estabelecidos no seu planejamento estratégico. A escolha fundamenta-se porque os autores deste estudo são participantes do Programa de Pós- 
graduação em Educação Profissional e Tecnológica (PPGEPT/CTISM), além de servidores da UFSM. O Colégio Politécnico é uma Unidade de Educação Básica, Técnica e Tecnológica da Universidade Federal de Santa Maria, prevista no Estatuto Geral da UFSM, vinculada à Coordenadoria de Educação Básica, Técnica e Tecnológica da UFSM. Tem por finalidade ministrar a Educação Básica, a Formação Inicial e Continuada, a Educação Profissional Técnica de Nível Médio e a Educação Profissional Tecnológica.

O processo de autoavaliação institucional é um instrumento extremamente relevante cuja finalidade é contribuir para o contínuo processo de aperfeiçoamento do desempenho da UFSM e das suas Unidades de Ensino, como é o caso do Politécnico. Entende-se que um estudo desta natureza contribui para que Universidades, suas Unidades e seus Participantes (Gestores, Docentes, Técnico-Administrativos e Discentes) analisem internamente, através de uma colaboração transparente e proativa dos sujeitos, suas ações, buscando sistematizar dados para analisá-los e interpretá-los com vistas à identificação de práticas bem-sucedidas, assim como a percepção de falhas, deficiências, enganos e omissões, a fim de evitá-los no futuro, bem como a preocupação em fortalecer determinadas áreas estratégicas.

\section{Importância da avaliação para as IES}

Entende-se por Avaliação Institucional, um dispositivo de mensuração dos dados internos das Instituições de Ensino Superior (IES), o qual estabelece parâmetros balizadores para obtenção de resultados institucionais, dando suporte ao planejamento estratégico das IES. (OLIVEIRA, 2014).

A Avaliação Institucional tem com o propósito de testar, medir e avaliar, através da interpretação de dados quali-quantitativos, fundamentados em padrões e critérios definidos. (ROSSIT; STORANI, 2010). O projeto de avaliação institucional da Universidade deve refletir o porquê, para quê e para quem existe, através da Avaliação Institucional. A avaliação deve ser permanente em seus múltiplos aspectos, a fim de se promover os ajustes necessários nos processos de ensino, pesquisa, administração e extensão de serviços à comunidade.

A Avaliação Institucional no Brasil, em nível governamental, vem numa tentativa constante de evolução, desde o ano de 1983 com o Programa de Avaliação da Reforma Universitária (PARU), até o ano de 2004, com o Sistema Nacional de Avaliação da Educação Superior (SINAES). O SINAES, inicialmente, apresentou 10 dimensões que foram, posteriormente, distribuídas em cinco eixos temáticos: Eixo 1 - Planejamento e Avaliação Institucional (Dimensão 8); Eixo 2 - Desenvolvimento Institucional (Dimensões 1 e 3); Eixo 3 
- Políticas Acadêmicas (Dimensões 2, 4 e 9); Eixo 4 - Políticas de Gestão (Dimensões 5, 6 e 10) e Eixo 5 - Infraestrutura Física (Dimensão 7).

A UFSM constituiu a Comissão Própria de Avaliação (CPA) a partir da exigência do SINAES, com a atribuição de condução dos processos internos de avaliação da instituição, de sistematização e de prestação das informações solicitadas pelo INEP. Concomitantemente, também criou as Comissões Setoriais de Avaliação (CSA's) para auxiliar nessa atribuição. A Regulamentação da CPA e das CSA's da UFSM se dá pela seguinte legislação: Lei Federal N. 10.861, de 14 de abril de 2004; Portaria MEC N. 2.051, de 9 de julho de 2004; Portaria UFSM N. 46.506, de 21 de julho de 2004; Resolução UFSM N. 008/04, de 23 de setembro de 2004 (Revogada) e Resolução UFSM N. 009/15,de 24 de abril de 2015.

Através da Resolução UFSM N. 009/15, de 24 de abril de 2015, em seus artigos $8^{\circ}$ e $9^{\circ}$, tem-se caracterizados a composição e atribuições dos membros da CSA em questão.

Art. $8^{\circ}$ As CSA junto à reitoria e às demais unidades envolvidas serão constituídas por:

I - representantes do corpo docente, técnico-administrativo em educação e discente da unidade, escolhidos pelo conselho da referida unidade, vedada a composição que privilegie a maioria absoluta de um segmento; $e$

II - coordenador, escolhido pelos seus membros.

$\S 1^{\circ}$ A CSA da reitoria não terá representante do corpo discente em virtude de sua especificidade.

$\S 2^{\circ}$ Os integrantes da CSA serão nomeados pelo diretor da unidade que se refere para um mandato de dois anos, permitida uma recondução.

Art. $9^{\circ}$ Compete às CSA:

I - sensibilizar a comunidade universitária da respectiva unidade para os processos de avaliação institucional;

II - desenvolver o processo de autoavaliação na unidade, conforme o projeto de autoavaliação da Universidade e orientações da CPA;

III - sistematizar e prestar as informações solicitadas pela CPA; $e$

IV - acompanhar os processos de avaliações interna e externa específicas dos cursos que compõem a unidade universitária.

A autoavaliação institucional é um instrumento norteador para o desenvolvimento integral dos cursos a serem ofertados pelo Colégio Politécnico na UFSM. Neste sentido, a Portaria n. 2.051 de 09 de julho de 2004, que regulamenta os procedimentos de avaliação do Sistema Nacional de Avaliação da Educação Superior (SINAES), instituído na Lei n. 10.861, Barbarói, Santa Cruz do Sul, n.53, p.<141-155>, jan./jun. 2019 
de 14 de abril de 2004, prevê a criação de comissões próprias de avaliação (CPA's) com o objetivo de proceder à autoavaliação nas instituições de ensino superior (IES). Em decorrência, o Projeto de Autoavaliação no Politécnico/UFSM pretende consolidar a autoavaliação de modo abrangente, sistêmico, contínuo, sintetizando as dez dimensões que definem a Instituição.

A finalidade do Projeto de Autoavaliação Institucional do Colégio Politécnico da UFSM é tornar a prática da autoavaliação institucional uma ação norteadora na tomada de decisões, gerando reflexão permanente das ações. Pretende-se, assim, fortalecer as relações da Instituição com a sociedade civil, enfatizando que o propósito da avaliação no Colégio Politécnico da UFSM tem caráter democrático, a partir dos seus cursos e de todas as outras atividades acadêmicas e culturais. Têm-se, também, como intuito de melhorar a qualidade dos serviços ofertados em várias instâncias e setores no Colégio Politécnico da UFSM, bem como promover o aprofundamento dos compromissos e responsabilidades sociais da IES por meio da valorização de sua missão institucional, da promoção dos valores democráticos, do respeito às diferenças e às diversidades, da afirmação da autonomia e da identidade institucional, bem como sistematizar e prestar informações solicitadas ao Instituto Nacional de Estudos e Pesquisas Educacionais Anísio Teixeira (INEP).

Com esse propósito, o Projeto de Autoavaliação Institucional, geralmente objetiva:

a) Produzir conhecimento sobre a realidade da IES;

b) Identificar os pontos fracos e fortes da IES, bem como suas causas e consequências;

c) Promover reflexões sobre a relação contexto institucional, objetivos da IES e cursos a serem ofertados;

d) Oferecer informações para subsidiar o processo de planejamento das diferentes instâncias da IES, indicando medidas que conduzam à execução de projetos acadêmicos administrativos relevantes;

e) Fortalecer as relações de cooperação entre os diversos segmentos da comunidade acadêmica;

f) Sensibilizar os diferentes segmentos da IES sobre a importância da autoavaliação como instrumento de melhoria da qualidade;

g) Consolidar uma autoavaliação contínua e formativa;

h) Identificar a inserção e o grau de participação da Instituição de Ensino Superior( IES), no atendimento às demandas da sociedade, tanto no que se refere à produção científica quanto à formação de profissionais;

Barbarói, Santa Cruz do Sul, n.53, p.<141-155>,jan./jun. 2019 
i) Verificar as ações desenvolvidas nas áreas de ensino, pesquisa e extensão e a coerência com a missão e as metas estabelecidas no Plano de Desenvolvimento Institucional;

j) Analisar de que maneira a estrutura organizacional favorece as condições para a execução das ações propostas no PDI;

k) Criar mecanismos que possibilitem a identificação, organização, catalogação e divulgação (interna e externa) da Instituição a fim de identificar em quais áreas e de que maneira a Comissão Própria de Avaliação responderá às demandas sociais.

As dimensões da Autoavaliação Institucional, conforme preconiza o SINAES, e que serão avaliadas pela CSA do Colégio Politécnico da UFSM, são as seguintes:

1) a Missão e o Plano de Desenvolvimento Institucional da UFSM;

2) a Política para o Ensino, a Pesquisa e a Extensão e as respectivas formas de operacionalização, juntamente com os procedimentos para estímulo à produção acadêmica e diferentes modalidades de bolsa;

3) a Responsabilidade Social da IES, considerando, especialmente, o que se refere à sua contribuição em relação à inclusão social, ao desenvolvimento econômico, à defesa do meio ambiente, da memória cultural da comunidade de Santa Maria;

4) a Comunicação com a sociedade;

5) as Políticas de Pessoal, as carreiras do corpo docente e do corpo técnicoadministrativo, seu aperfeiçoamento e desenvolvimento profissional e suas condições de trabalho;

6) a Organização e Gestão da IES, especificamente o funcionamento, representatividade, independência e autonomia dos colegiados na relação coma a mantenedora e a participação dos segmentos da comunidade acadêmica nos processos decisórios de sua competência;

7) a Infraestrutura física, especialmente a que se refere ao ensino e pesquisa, tais como biblioteca, recursos de informação e comunicação;

8) o Planejamento e a Avaliação, com ênfase nos processos, resultados e eficácia da autoavaliação institucional;

9) as Políticas de Atendimento ao Estudante;

10) a Sustentabilidade Financeira, considerando o significado social da continuidade dos compromissos na oferta da educação superior. 
Quanto à metodologia de aplicação da autoavaliação no Colégio Politécnico da UFSM, os instrumentos de autoavaliação Institucional integrarão todos os segmentos da IES: corpo discente, corpo docente, direção, coordenação e funcionários técnico-administrativos.

Os instrumentos de autoavaliação institucional serão questionários específicos para cada um dos segmentos a serem avaliados, de acordo com as dez dimensões da autoavaliação institucional estipuladas pelo Sistema Nacional de Avaliação do Ensino Superior - SINAES. O intuito é que cada integrante da IES realize a avaliação da mesma a partir de sua contextualização específica e que seja igualmente avaliado.

No processo de autoavaliação da CSA do Colégio Politécnico da UFSM, os docentes e coordenadores serão individualmente avaliados, bem como os aspectos de infraestrutura, projeto político-pedagógico e plano de desenvolvimento institucional.

Para a organização e estruturação da autoavaliação Institucional será considerada uma gama de indicadores de desempenho, contendo aspectos qualitativos e quantitativos, os quais so Colégio Politécnico da UFSM

A metodologia envolverá, tendo por pressuposto a busca participativa da qualidade e eficácia institucional, o diálogo permanente entre a Comissão Própria de Avaliação e as diferentes instâncias institucionais, a aplicação de instrumentos quantitativos e qualitativos e a reflexão sobre os indicadores obtidos numa perspectiva formativa, dialética, propositiva e transformadora. É também condição fundamental para a efetiva autoavaliação o entendimento da avaliação não como punição ou premiação, mas como o caminho para o desenvolvimento da instituição a partir dos resultados obtidos.

Por sua natureza complexa, uma proposta de autoavaliação, deverá envolver a participação da comunidade acadêmica e representantes da sociedade na discussão do estabelecimento de indicadores, de formas para a avaliação, bem como na definição de tomadas de decisões decorrentes dos resultados obtidos.

Para a coleta de dados, serão utilizados documentos institucionais, análises situacionais, questionários específicos e outras fontes necessárias à construção de um amplo processo de discussão e reflexão sobre as diversas especificidades e atividades institucionais e que permitam o aprofundamento e compreensão sobre as dimensões avaliadas. O que se pretende é uma avaliação que tenha um caráter global, avaliando a instituição em uma abordagem qualitativa, por meio de discussões em grupo, mediada por um moderador, a partir de um roteiro previamente com a finalidade de coletar expectativas e desejos da comunidade acadêmica e dos representantes da sociedade a respeito do papel e do futuro do Colégio 
Politécnico da UFSM e uma abordagem quantitativa, elaborada por meio da aplicação de questionários específicos que contemplem as dimensões propostas pelo CONAES.

\section{Avaliação Institucional do Colégio Politécnico da UFSM}

De acordo com a representação da Figura 1, a Avaliação Institucional na UFSM ocorre com o suporte e assessoria da Coordenadoria de Planejamento e Avaliação Institucional da UFSM (COPLAI), a qual apoia e assessora a Comissão Própria de Avaliação (CPA/UFSM) e a Comissão Setorial de Avaliação (CSA) de todas as unidades de ensino/UFSM, que por sua vez, gerenciam e auxiliam a autoavaliação (docente e interna) e o recredenciamento institucional. A CPA também apoia a avaliação institucional e dos cursos, realizada por comissões externas de avaliação, constituídas por avaliadores do Basis/MEC/INEP e também a avaliação ENADE.

Figura 1 - Funcionamento da CPA/UFSM

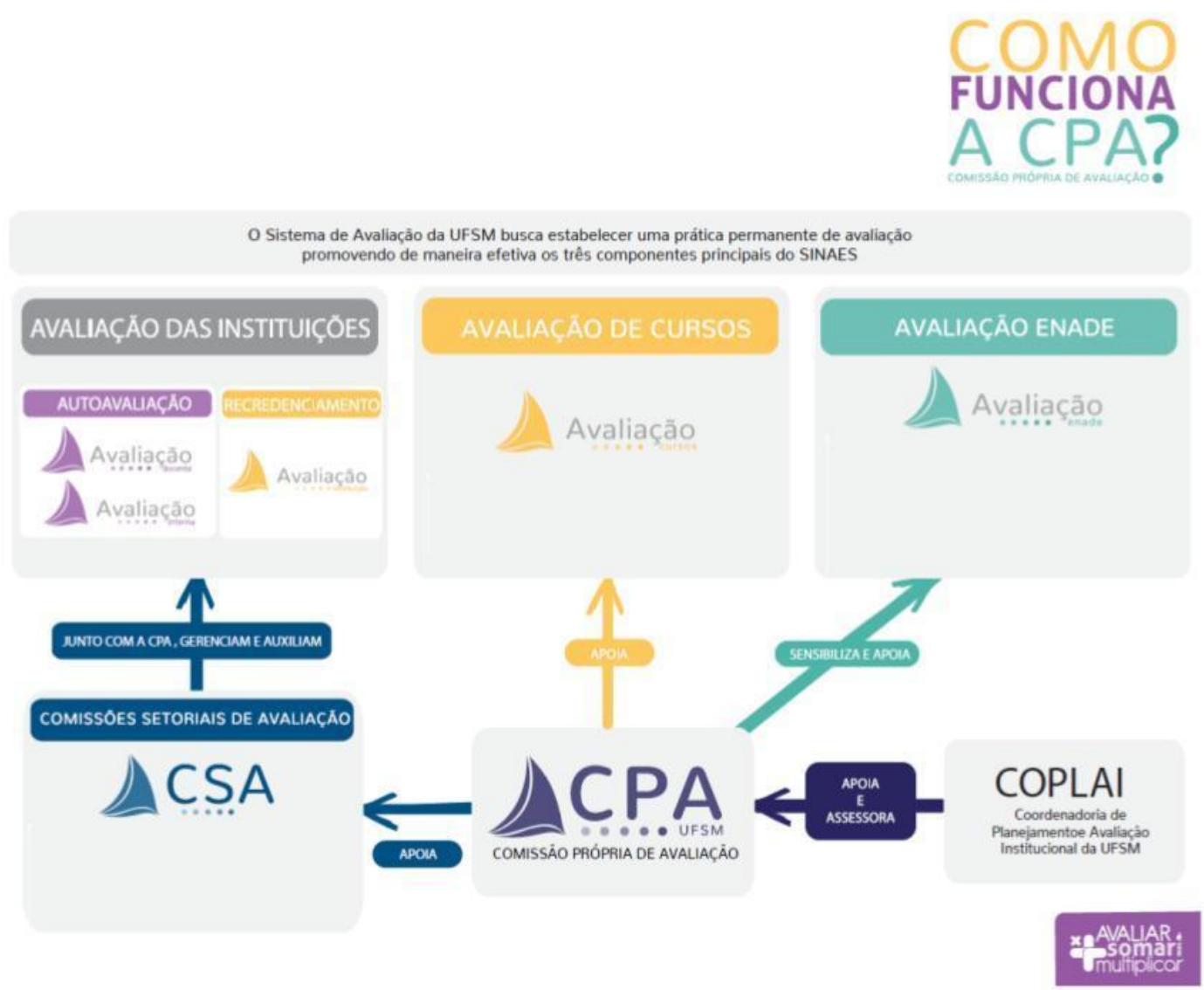

Fonte: Adaptado de CPA/UFSM (2015). 
A Avaliação Institucional, é a forma que a UFSM tem para identificação de suas potencialidades e fragilidades, que ajudam a definir prioridades que efetivem o seu desenvolvimento. A Avaliação Institucional é composta de três modalidades: a avaliação interna, a avaliação externa e a avaliação dos estudantes. O processo de avaliação interna, também chamado de autoavaliação, é coordenado pela Comissão Própria de Avaliação (CPA) de cada Instituição, enquanto a avaliação externa é realizada por comissões designadas pelo MEC/INEP.

Com base nestas considerações, entende-se que a avaliação interna é, portanto, um processo cíclico, criativo e renovador de análise, interpretação e síntese das dimensões que definem a instituição. Dessa forma, as informações produzidas pelas avaliações em larga escala, permitem a implementação de ações mais condizentes com a oferta de uma educação de qualidade e promoção da equidade de oportunidades educacionais. Como as informações produzidas a partir de um sistema de avaliação têm papel importante sobre os rumos do sistema de ensino, além do cuidado na garantia da fidedignidade das informações oferecidas, é fundamental garantir a reflexão sobre esses resultados e constante melhoria na sua produção, seja pelo envolvimento crescente de todos os participantes do processo, seja pelo aprimoramento de métodos, instrumentos e logística de realização da avaliação (ROSSIT; STORANI, 2010).

\section{Metodologia}

\section{Tipo de pesquisa}

Este trabalho consiste em uma investigação documental, baseada numa abordagem quantitativa, referente à análise dos dados orçamentário-financeiros da CSA/Politécnico. Esses dados são referentes ao Orçamento de Despesa da Comissão Setorial de Avaliação Institucional/Politécnico. Define-se análise documental como "uma operação ou um conjunto de operações visando representar o conteúdo de um documento sob uma forma diferente da original, a fim de facilitar num estado ulterior, a sua consulta e referenciação". (BARDIN, 2016, p.45). A pesquisa documental foi realizada conforme um estudo de caso, que, no entendimento de Gil (2010), é uma técnica de pesquisa que compreende um estudo de um ou mais objetos, de forma que permita seu amplo e detalhado conhecimento, neste caso, a CSA/Politécnico da UFSM. 


\section{Coleta de dados}

Para coleta dos dados foram utilizados relatórios com indicadores do Sistema de Informações Educacionais (SIE), obtidos junto à Direção de Administração do Órgão. Esses dados são referentes ao Orçamento de Despesa da Comissão Setorial de Avaliação Institucional/Politécnico. Foram avaliadas duas formas de aplicação do orçamento previsto em cada ano (2015 a 2017), sendo estas: Itens Empenhados pela Gestão e Período e, Transferência de Recursos.

\section{Análise dos resultados}

Para análise dos dados orçamentário-financeiros constantes nos relatórios obtidos, foi utilizada a técnica de estatística descritiva. A estatística descritiva, conforme Loesch (2012), tem como finalidade resumir o conjunto de todos os dados coletados em uma dada investigação a relativamente poucos números e gráficos. A ideia básica é a de se estabelecer uma descrição dos dados relativos a cada uma das variáveis, dados esses levantados através de uma amostra. Esta técnica de análise dos resultados é importante, uma vez que ela sintetiza os valores de mesma natureza e os coloca de forma organizada para uma fácil compreensão dos resultados.

Neste estudo utilizamos para análise um quadro e um gráfico, que resultaram da análise das planilhas obtidas junto à Direção de Administração do Colégio Politécnico/UFSM, avaliando-se as duas categorias já citadas na coleta de dados.

\section{Resultados}

Baseado nos relatórios obtidos no SIE construiu-se um quadro orçamentáriofinanceiro (Figura 2), com abordagem diagnóstica da aplicação dos recursos da CSA/Politécnico. Nele são apresentados os valores investidos no triênio 2015-2017.

A destinação dos recursos engloba vários itens e, neste artigo foi empregada a divisão em 4 dimensões, baseando-se na afinidade da destinação. A dimensão "auxílio e capacitação" refere-se aos investimentos direcionados a pesquisas e desenvolvimento de estudos tanto para alunos quanto para capacitação de servidores, incluindo bolsas e diárias para participação em eventos científicos. A dimensão "biblioteca" trata da aquisição de materiais didáticos, principalmente livros e periódicos científicos. A aquisição de cadeiras universitárias, computadores ou condicionadores de ar são exemplos de melhorias do espaço acadêmicos e contemplados na dimensão "equipamentos". Por fim, a dimensão "consumo" refere-se ao 
material de consumo da comunidade e de apoio para divulgação de atividades e projetos do Colégio Politécnico/UFSM.

Figura 2 - Quadro da distribuição dos investimentos do Colégio Politécnico/UFSM

\begin{tabular}{|c|c|c|c|c|c|c|}
\hline \multirow{2}{*}{$\frac{\circ}{\delta}$} & \multirow{2}{*}{ 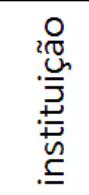 } & \multicolumn{5}{|c|}{ valores em $\mathrm{R} \$$} \\
\hline & & $\begin{array}{c}\text { auxílio e } \\
\text { capacitação }\end{array}$ & biblioteca & equipamentos & consumo & total liberado \\
\hline 埚 & POLI & 0,00 & 0,00 & 0,00 & 0,00 & $47.433,00$ \\
\hline $\begin{array}{l}0 \\
\stackrel{1}{N}\end{array}$ & POLI & $19.645,00$ & $16.300,61$ & $3.899,39$ & $22.508,93$ & $62.459,88$ \\
\hline 공 & POLI & $3.450,00$ & $12.667,06$ & $26.671,99$ & $20.710,00$ & $63.499,05$ \\
\hline
\end{tabular}

Fonte: Elaboração própria (2017).

É possível observar no quadro da Figura 2 que apenas no ano de 2015, data de implantação das CSA's na UFSM, a verba anual de R\$ 47.433,00 não recebeu destinação orçamentária. No ano seguinte, em 2016, as quatro dimensões foram contempladas com recurso total de $\mathrm{R} \$ 62.459,88$, sendo que a maior aplicação ocorreu para a dimensão consumo (R4 22.508,93). Já em 2017, o total de recurso foi de $\mathrm{R} \$ 63.499,05$, sendo que a maior aplicabilidade ocorreu na dimensão equipamentos ( $\mathrm{R} \$ 26.671,99)$. Também pode se observar que as dimensões biblioteca e consumo tiveram menor variação de aplicação entre 2016 e 2017, enquanto que nas dimensões auxílio e capacitação e equipamentos, essa variação foi bem maior. As diferentes aplicações dos recursos a serem destinados nas determinadas dimensões, a cada ano, segue determinação da CSA.

A partir do quadro, construiu-se o gráfico da Figura 3, que expõe visualmente tais dados, onde se tem o demonstrativo dos investimentos, com a aplicação anual dos recursos. 
Figura 3 - Gráfico orçamentário-financeiro dos valores investidos pelo Colégio Politécnico no triênio 2015-2017

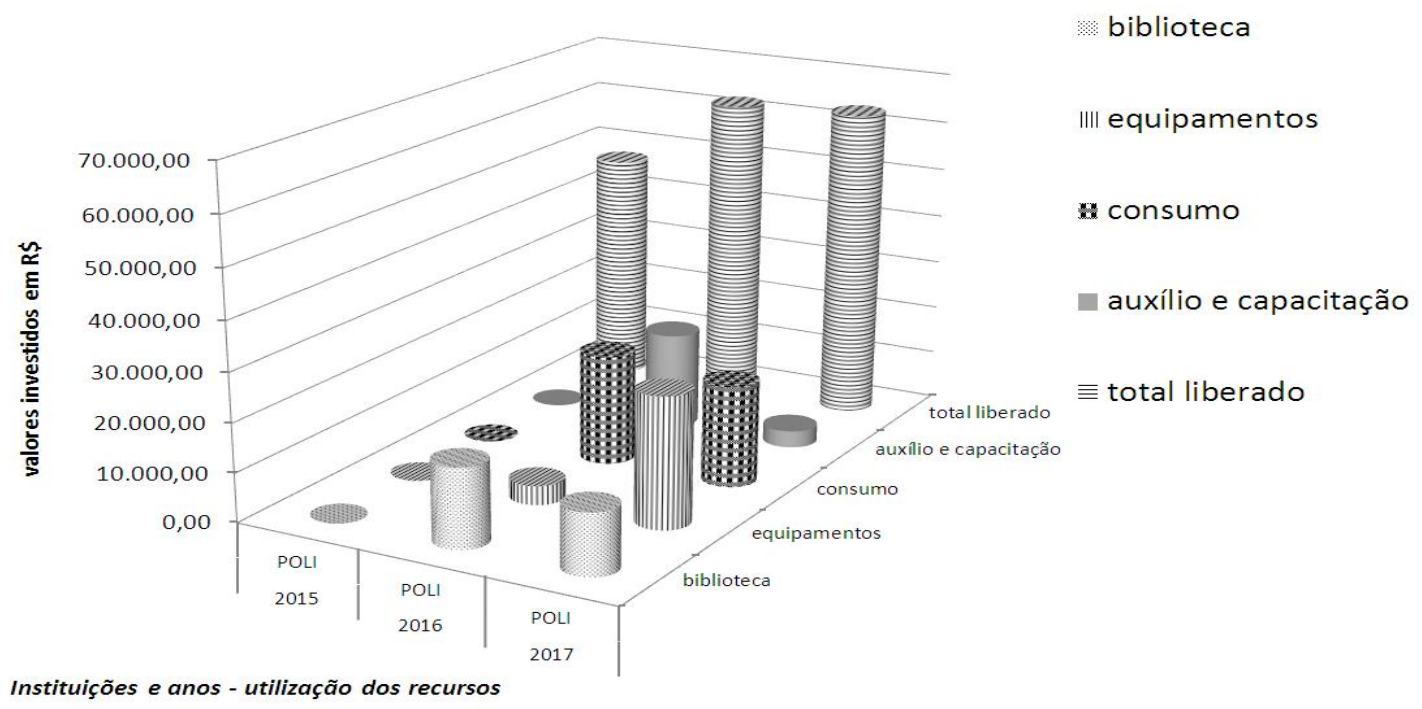

Fonte: Elaboração própria (2017).

A partir da Figura 3 evidencia que, embora todo o investimento seja importante no incremento da educação, observou-se que a primeira dimensão mais contemplada em 2016 foi a de consumo para o apoio na divulgação de atividades e projetos do Colégio Politécnico/UFSM. Em segundo lugar, foi para auxílio e capacitação, onde a valorização humana tem papel fundamental, refletindo na motivação de todos, além da divulgação da pesquisa científica realizada no Colégio Politécnico/UFSM em eventos científicos.

Do mesmo modo, percebe-se a preocupação da CSA em priorizar a compra de livros no biênio 2016-2017, fundamental para a manutenção e atualização da biblioteca, reconhecendo-a como mediadora da informação para formação acadêmica. Este quesito faz parte da avaliação da qualidade dos cursos pelo MEC/INEP, tendo em vista que na avaliação in loco o instrumento de avaliação do Basis utilizado, vai influenciar na avaliação e nota final do curso. Já em 2017, observou-se um investimento significativo em equipamentos. Este tipo de rubrica resulta em manutenção das instalações e atualização dos materiais de pesquisa/ensino, promovendo a melhoria nas condições de aprendizagem do ambiente acadêmico.

Esses resultados mostram que a CSA/Politécnico está ativamente auxiliando na construção do ensino da instituição, e através deles pode refletir sua mudança e melhorias futuras na aplicação dos recursos orçamentários. 


\title{
Considerações finais
}

Neste artigo foram apresentados dados relacionados com a destinação de recursos financeiros pela CSA/Politécnico da UFSM no triênio 2015-2017, bem como a sua relação com a Avaliação Institucional, esclarecendo a destinação destes recursos, através de indicadores da aplicação dos recursos no auxílio do desenvolvimento de estudos, contribuindo para as ações de ensino, pesquisa e extensão.

Verificou-se que a distribuição orçamentário-financeira da CSA/Politécnico, alcançou as metas presentes nos critérios de efetividade e qualidade, com constante aperfeiçoamento, mesmo com limitações, para atingir uma avaliação formativa considerando especificidades do planejamento institucional. Neste sentido, é importante que as coordenações de curso procurem um caminho para uma maior sensibilização junto aos discentes, no que tange a participação e divulgação de suas pesquisas científicas, através da disponibilidade orçamentário-financeira de auxílio para desenvolvimento de estudos e pesquisas. É imprescindível que toda a comunidade acadêmica esteja engajada no processo de avaliação, para um melhor resultado.

Como contribuição deste artigo, tem-se a divulgação do orçamento financeiro da CSA/Politécnico, importante para a transparência pública dos dados, bem como demonstrar quais destinações são determinadas para o recurso financeiro e futuros planejamentos, além de ser útil na identificação de ações e propósitos estabelecidos no planejamento estratégico da UFSM. E também, divulgar o modelo do Sistema de Avaliação da Instituição para tornarem efetivas as exigências do SINAES.

\section{SECTOR ASSESSMENT COMMITTEE OF THE POLYTECHNICAL COLLEGE (UFSM): ANALYSIS OF THE BUDGETARY-FINANCIAL}

\begin{abstract}
The objective of this study is to analyze the budgetary-financial diagnosis of the Polytechnic Sector Evaluation Commission, linked to the Federal University of Santa Maria, in order to identify the actions of the said Commission in regard to financial resources from the institution's Self Evaluation Commission. From the methodological point of view, this is a research-documentary research with a descriptive-quantitative approach, using the method described and from the perspective of a case study in the Polytechnic College. For data collection, indicators of the Educational Information System were obtained from the administrative sector. This analysis allowed the disclosure of the financial budget of the $\mathrm{CSA} /$ Polytechnic, as well as the demonstration of the use of financial resources directed to the actions and purposes established in UFSM's strategic planning.
\end{abstract}

Keywords: UFSM Polytechnic College. Self Evaluation Commission (CPA). Sectorial Evaluation Committee (CSA). Budget-Financial Diagnosis. 


\title{
COMISIÓN SECTORIAL DE EVALUACIÓN DEL COLEGIO POLITECNICO (UFSM): DIAGNÓSTICO PRESUPUESTARIO FINANCIERO
}

\begin{abstract}
Resúmen
Este estudio tiene como objetivo analisar el presupuesto financiero de la Comisión Sectorial de Evaluación del Colegio Politecnico, vinculado a la Universidad Federal de Santa Maria, con la finalidad de identificar las acciones de dicha Comisión en el direccionamiento de los recursos financieros, originarios de la Comisión Propia de Evaluación de la institución. Del punto de vista metodologico, esta es una pesquisa investigativo-documental con abordaje descriptivo-cuantitativo, valiendo del metodo descripto y por la optica de un estudio de caso en el Colegio Politecnico/UFSM. Para colecta de datos fueron utilizados indicadores del sistema de informaciones educacionales, obtenidos junto a la dirección administrativa del órgano. Este análisis permitió la divulgación del presupuesto financiero de la CSA/ Politecnico, así como la demostración del uso de recursos financieros dirigidos a las acciones y propósitos establecidos en la planificación estratégica de UFSM.

Palabras clave: Colegio Politecnico de la Universidad Federal de Santa Maria. Comisión Propia de Evaluación (CPA). Comisión Sectorial de Evaluación (CSA) Diagnostico Presupuesto Financiero.
\end{abstract}

\section{REFERÊNCIAS}

BARDIN, Laurence. Análise de conteúdo. São Paulo, SP: Edições 70, 2016.

BRASIL. Lei no 10.861, de 14 de abril de 2004. Institui o Sistema Nacional de Avaliação da Educação Superior (SINAES) e dá outras providências. Disponível em:

<http://www.inep.gov.br>. Acesso em 07 maio 2017.

. MEC -Diretrizes para a avaliação das instituições de educação superior.

Brasília: INEP/CONAES, 2004.

DAVIS, Claudia; GROSBAUM, Marta Wolak. Sucesso de todos, compromisso da escola. In: VIEIRA, Sofia Lerche (Org.). Gestão da escola: desafios a enfrentar. Rio de Janeiro: DP\&A, 2002.

GIL, Antonio Carlos. Como elaborar projetos de pesquisa. 5 ed. São Paulo: Atlas, 2010.

LOESH, Claudio. Estatística e probabilidades. Rio de Janeiro: LTC, 2012.

OLIVEIRA, Francisco Nilton Gomes de. Educação Superior: refletindo caminhos e compartilhando relatos de experiências. Curitiba: CRV, 2014.

ROSSIT, Rosana Aparecida Salvador; STORANI, Karin (Orgs.). Avaliação nos Processos Educacionais. São Paulo:EditoraFap-Unifesp, 2010.

UNIVERSIDADE FEDERAL DE SANTA MARIA. Comissão Própria de Avaliação. Como funciona a CPA. Disponível em: <http://coral.ufsm.br/avaliacaoufsm/index.php/cpa/comofunciona-a-cpa>. Acesso em: 25 out. 2017. 
UNIVERSIDADE FEDERAL DE SANTA MARIA. Comissão Própria de Avaliação.

Legislação interna. Disponível em:

<http://coral.ufsm.br/cpa/images/documentos/regimento.pdf >. Acesso em: 26 out. 2017.

Data de recebimento: $31 / 07 / 2018$

Data de aceite: 17/09/2019

\section{Sobre os autores:}

Juliano Molinos de Andrade é graduado em Física Licenciatura e Mestre em Educação Profissional e Tecnológica pela UFSM. Técnico-administrativo da UFSM. Endereço Eletrônico: julianomolinos@ gmail.com

Adriane Terezinha Filipetto é graduada em Farmácia e Bioquímica pela UFSM e Especialista em Gestão de Recursos Humanos pela UNINTER. Mestre em Educação Profissional e Tecnológica pela UFSM. Técnico-administrativa da UFSM. Endereço Eletrônico: atfilipetto@yahoo.com.br

Olga Etelvina da Costa Rohde é graduada em Fisioterapia e Especialista em Fisioterapia Abordagem Corporal Interdisciplinar pela UFSM. Mestre em Educação Profissional e Tecnológica pela UFSM. Técnico-administrativa da UFSM. Endereço Eletrônico: olgarohde@gmail.com

Francisco Nilton Gomes de Oliveira é graduado em Terapia Ocupacional e Mestre em Psicologia pela UFC, Doutor em Linguística pela UFPE e Pós Doutor em Educação na UFGRS. Professor adjunto do Departamento de Terapia Ocupacional e do Mestrado em Educação Profissional e Tecnológica da UFSM. Endereço Eletrônico: niltonoliveira@superig.com.br 